DOI: $10.34185 / 1991-7848.2021 .01 .05$

УДК 621.9.015:621.9.019

Я.М. Кусий, О.В. Личак ${ }^{5}$

\title{
ВПЛИВ ЕЛЕМЕНТІВ КОНСТРУКЦІЇ ВИЛИВКА НА ЕВОЛЮЦІЮ ТЕХНОЛОГІЧНИХ ДЕФЕКТІВ
}

Формування властивостей заготовок під час заливання та кристалізації рідкого розплаву вимагає застосування ефективних критеріїв комплексної оцінки деградації матеріалу при формоутворенні виливків. Запропоновано застосувати метод LM-твердості та критерій технологічної пошкоджуваності для аналізу структурних змін при виготовленні литих заготовок, згідно якого визначається схильність матеріалу до формування технологічних дефектів за ступенем розсіювання характеристик твердості матеріалу на етапі конструкторськотехнологічної підготовки виробництва. Показано доцільність використання розробленої методики при аналізі впливу розміщення конструктивних елементів виливка із алюмінієвого сплаву на прогнозування розвитку структурних дефектів і неоднорідностей у матеріалі виробу.

Ключові слова: заготовка, виливок, життєвий цикл виробу, технологічний процес, технологічне успадковування, гомогенність, технологічна пошкоджуваність

\section{Постановка проблеми}

Експлуатаційні характеристики та показники надійності виробів разом iз регламентованими технічними умовами (ТУ) їх параметрами якості тісно пов'язані 3 важливими етапами та стадіями життєвих циклів деталей машин [1, 2]. Еволюція технології машинобудування базується на таких основних напрямках [3]: розроблення наукових основ цілеспрямованої формозміни заготовки; економія дорогих матеріалів, забезпечення експлуатаційних характеристик та показників надійності виробів; скорочення етапу технологічної підготовки виготовлення нових виробів при дотриманні ТУ; моделювання технологічних процесів механічного оброблення деталей i складання машин тощо. Істотні розбіжності між прогнозованими та реальними значеннями функціональних параметрів поведінки виробів на важливих етапах і стадіях їх життєвих циклів свідчать про нефективність вирішення поставлених проблем лише за допомогою теоретичних методів [1, 2]. Відзначається [4, 5], що дослідження фізичних процесів зношування, втоми, корозії тощо у поєднанні із імовірнісними методами є найраціональнішим напрямком подальшого розвитку технологічного забезпечення параметрів якості виробів, їх експлуатаційних характеристик і показників надійності.

(c) Кусий Я.М., Личак О.В., 2021 
На сьогоднішній день не завжди ефективними $є$ існуючі критерії комплексної оцінки деградації матеріалу виробу як при його виготовленні, так i при подальшій експлуатації із врахуванням спадкових властивостей матеріалу у технологічному ланцюжку заготовка-кінцевий виріб [6].

Відсутність раціонального критерію комплексної оцінки деградації матеріалу виробу $є$ особливо відчутною на етапі виробництва заготовок виробів. Недосконалою $є$ традиційна методика вибору заготовки при розробленні технологічних процесів, що зводиться до порівняння альтернативних методів отримання заготовки за критерієм технологічної собівартості, нехтуючи сформованими в заготівельних цехах відправними експлуатаційними характеристиками деталей машин. В сучасній науковотехнічній літературі недостатньо враховується роль заготівельних операцій і при аналізі впливу технологічної спадковості на параметри якості кінцевого виробу. Відправну структуру та початкові властивості заготовок потрібно розглядати в тісному взаємозв'язку із спадковістю металу, починаючи із виплавки розплаву. Першим етапом виготовлення будь-якої заготовки $є$ отримання виливків на металургійному підприємстві. Відомо, що усього $25 \%$ властивостей вихідної шихти передається заготовці, а близько 75 \% формується під час заливки та кристалізації при охолоджуванні [3, 6]. Технологічні фактори, що виникають у відправному металургійному процесі і при здійсненні ковальсько-штампувальних i термічних операцій у кузні, проходять в подальшому через повний технологічний ланцюг формозміни виробів і суттєво впливають на формування необхідних експлуатаційних характеристик виконавчих поверхонь [3].

Розроблення та дослідження раціональних критеріїв комплексної оцінки деградації матеріалу виробу по технологічному ланцюжку відправна заготовкакінцевий виріб інтенсифікувало б роботи стосовно створення науково обгрунтованої методології із ефективним керуванням усього циклу робіт 3 проектування та вдосконалення взаємозв'язків заготовка (виріб) технологічна система.

\section{Аналіз останніх досліджень і публікацій}

В роботах [1, 2, 7, 8] встановлено, що локальна природа руйнування в процесі зняття шару металу лезовою обробкою визначає потребу в аналізі процесу накопичення технологічних дефектів у матеріалах і сплавах при їх механічному обробленню та прогнозування їх «переродження» у технологічні пошкодження при несприятливих умовах експлуатації виробів. Загалом процес руйнування включає такі етапи [9]:

1) нагромадження дефектів, формування технологічних пошкоджень $\mathrm{i}$ порушення цілісності матеріалу у полі дії напружень та деформацій;

2) розвиток мікротріщин у дефектному середовищі; 
3) розвиток тріщин і відокремлення частинок матеріалу при заданих на межах заготовки питомих навантаженнях і переміщеннях.

Під пошкоджуваністю розуміють еволюційний процес нерівномірної зміни геометричної форми і розмірів контактуючих поверхонь спряжених деталей, структури і властивостей матеріалу поверхневих шарів. Наслідком пошкоджуваності $є$ пошкодження, що характеризується зміною структури, геометричних і фізико-механічних властивостей поверхневих шарів виробу під час його експлуатації [10, 11].

Для механіки пошкоджуваного середовища справедлива математична залежність [12]:

$$
\tilde{M}=M /\left(1-D_{M}\right),
$$

де $M, \tilde{M}$ - відповідно величини істинної та ефективної властивостей оброблюваного матеріалу виробу; $D_{M}$ - кінетика накопичення пошкоджень (пошкоджуваність) для заданої властивості матеріалу деталі.

У класичних роботах механіки, що описують пошкоджуваність виробів, i формування не пов'язують із структурою матеріалів. Лише при застосуванні енергетичних концепцій для опису процесів нагромадження пошкоджень встановлено [9], що в результаті в’язко-пластичної деформації формуються два види мікропошкоджень - по тілу і по границях зерен.

Визначальну роль у формуванні технологічних пошкоджень і процесах міжзеренного руйнування сплавів мають великокутові границі зерен. Вплив меж розподілу різного походження на процеси деформування та руйнування сплавів $є$ невивченим. Значною мірою це пояснюється неврахуванням в існуючих моделях меж зерен будови i структурно-фазового стану приграничних зон зерен [13].

У практиці матеріалознавства та технології машинобудування відомі методи оцінки ступеню пошкоджуваності матеріалу на підставі напрацювання за результатами як прямих (методи виважування, металографії тощо), так і непрямих (омічного опору, акустичної емісії тощо) вимірювань механічних характеристик металу без руйнування [14]. Застосування вказаних способів для оцінювання деградації матеріалу в результаті накопичення пошкоджень під час напрацювання супроводжується великими похибками, оскільки взаємозв'язок між вимірюваними параметрами та характеристиками структурно-фазового стану для широкої номенклатури матеріалів неоднозначний та грунтовно не вивчений.

3 відомих методів оцінки найпридатнішим за своїм технічним змістом $€$ спосіб вимірювання твердості матеріалу виробу на визначених стадіях напрацювання. Після цього, враховуючи кореляції механічних характеристик,зокрема твердості, із параметрами структури, оцінюють ступінь 
пошкоджуваності матеріалу. Даний спосіб є неінформативним і неточним, оскільки між твердістю матеріалу та його технологічною пошкоджуваністю кореляція слабка та не завжди однозначна [13].

Поряд з тим при вирішенні прикладних інженерних завдань застосовують метод LM-твердості, розроблений під керівництвом академіка А.О. Лебедєва. Характерною особливістю методу LM-твердості $€$ використання для аналізу пошкоджуваності матеріалу не абсолютного значення, а ступеня розсіювання характеристик механічних властивостей матеріалу на зруйнованих зразках після напрацювання при різних рівнях напружень. Даний метод найпростіше реалізувати, використовуючи як механічну характеристику твердість, значення якої застосовують для непрямої оцінки властивостей матеріалів [14-17].

Параметром, що інтегрально характеризує стан матеріалу під час опрацювання результатів вимірювань твердості, $€$ гомогенність, яка оцінюється за коефіцієнтом Вейбулла $(m)[14,16]$ :

$$
m=\frac{d(n)}{2.30259 \cdot S(\lg (H))},
$$

де $d(n)$ - параметр, що визначається кількістю вимірювань $n$;

$$
\begin{gathered}
S(\ell(H))=\sqrt{\frac{1}{n-1} \cdot \sum_{i=1}^{n}\left(\ell g\left(H_{i}\right)-\overline{\ell g(H)}\right)^{2}}, \\
\overline{\ell g(H)}=\frac{1}{n} \cdot \sum_{i=1}^{n} \lg \left(H_{i}\right) .
\end{gathered}
$$

Аналіз деградації властивостей матеріалу деталей машин проводять також при застосуванні коефіцієнта варіації $[14,16]$ :

$$
v=\frac{1}{\bar{H}} \cdot \frac{1}{\sqrt{\frac{1}{n-1} \cdot \sum_{i=1}^{n}\left(H_{i}-\bar{H}\right)^{2}}},
$$

де $\bar{H}$ - середнє значення твердості.

Для аналізу фактичної пошкодженості матеріалу виробів в результаті перетворення технологічних дефектів у технологічні пошкодження при несприятливих умовах експлуатації авторами $[15,17]$ запропоновано параметр $\Delta m$, а для оцінки інтенсивності зростання пошкодженості - характеристику $\delta$ :

$$
\begin{gathered}
\Delta m=\frac{m_{n}-m_{n m}}{m_{n}}, \\
\delta=\frac{m_{n}-m_{n m}}{m_{n m}},
\end{gathered}
$$

де $m_{n}, m_{n m}$ - значення коефіцієнтів гомогенності Вейбулла $(m)$, виміряні відповідно для початкового і поточного стану матеріалу виробу. 
При механічному обробленні виробу за відомим розподілом коефіцієнта гомогенності Вейбулла $(m)$ доцільно аналізувати деградацію структури матеріалу за його технологічною пошкоджуваністю $D[6,11,13]$ :

$$
D=1-\frac{m_{i}}{m_{\text {matr }}},
$$

де $m_{i}-$ значення коефіцієнта Вейбулла для $i$-го із n перерізів; $m_{\text {matr. }}-$ значення коефіцієнта Вейбулла для основного матеріалу виробу.

Мета дослідження. Метою даного дослідження $є$ дослідження впливу конструктивних елементів виливка для .

\section{Викладення основного матеріалу дослідження}

3 огляду на складнощі теоретичних методів аналіз впливу конструктивних елементів виливка на деградацію структури його матеріалу проведено на підставі експериментальних досліджень.

\section{Підготовка та реалізація експериментальних досліджень}

В піщано-глинясту форму було відлито плоску заготовку із розмірами 165х155x22 мм з матеріалу АК21M2.5Н2.5 ГОСТ 1853-93 (табл. 1, рис. 1). Край виливка, його випори і ливник було відрізано пилою при подачі МОР у зону різання. Температурний режим охолодження виливка $-690-710^{\circ} \mathrm{C}$.

Таблиця 1

Хімічний склад матеріалу виливка

\begin{tabular}{|l|l|l|l|}
\hline Хімічний елемент & Відсоток, \% & Хімічний елемент & Відсоток, \% \\
\hline $\mathrm{Al}$ & $70.953 \pm 0.080$ & $\mathrm{Mn}$ & $0.255 \pm 0.008$ \\
\hline $\mathrm{Si}$ & $23.219 \pm 0.078$ & $\mathrm{Cr}$ & $0.184 \pm 0.008$ \\
\hline $\mathrm{Cu}$ & $2.895 \pm 0.012$ & $\mathrm{~S}$ & $0.114 \pm 0.007$ \\
\hline $\mathrm{Fe}$ & $1.119 \pm 0.011$ & $\mathrm{Ni}$ & $0.084 \pm 0.003$ \\
\hline $\mathrm{Zn}$ & $1.096 \pm 0.006$ & $\mathrm{Ti}$ & $0.083 \pm 0.013$ \\
\hline
\end{tabular}

Після кристалізації виливка профрезерували його базову поверхню на вертикально-фрезерному верстаті мод. 6Р12 кінцевою фрезою $\varnothing 30$ мм. Окрім того розділили відправну заготовку на три зразки 3 концентраторами напружень: 3 ливником, малим і великим випорами (рис. 2). Метою експериментальних досліджень було встановити вплив розміщення ливника та малого випора на еволюцію технологічних дефектів у матеріалі від поверхні до матриці та виявити дефектний шар із максимальною кількістю технологічних пошкоджень, що підлягає видаленню у стружку. 

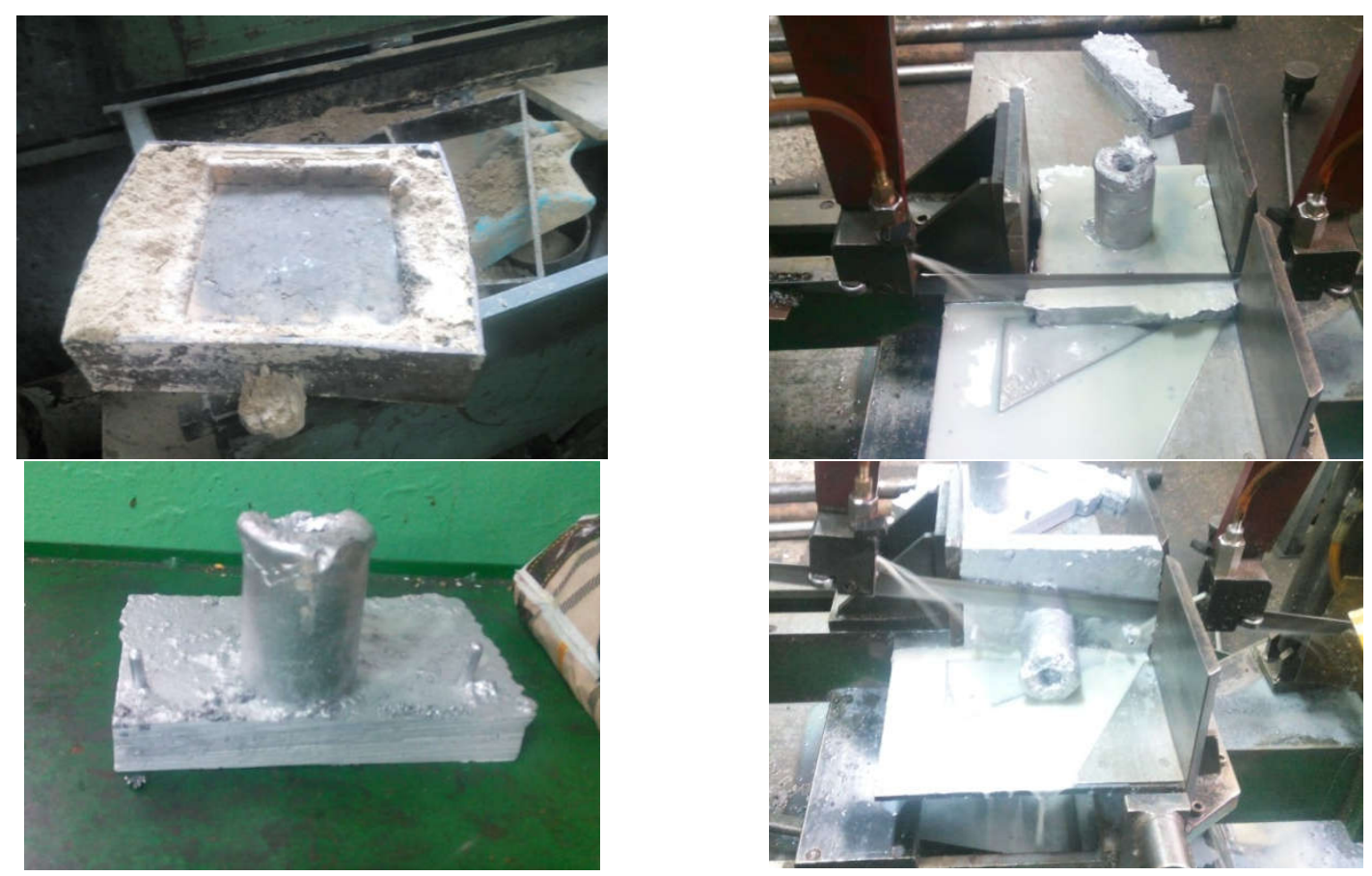

Рисунок 1 - Технологічний процес виготовлення виливка у піщано-глинястій формі

Торцеві сторони 1 і 2 зразків (рис. 2) двічі почергово фрезерували на універсально-фрезерному верстаті мод. 676 (B=2 мм; $\mathrm{t}=45$ мм; $\mathrm{S}_{\mathrm{xв}}=42 \mathrm{Mм} / \mathrm{xB}$; $\left.\mathrm{n}=640 \mathrm{xB}^{-1}\right)$ кінцевою фрезою $\varnothing 45 \mathrm{Mм}(\mathrm{z}=2)$. Після кожного фрезерування вимірювали твердість у п'яти перерізах (по 30 значень) на відстанях 2, 4, 7, 12, 17 мм від поверхні виливка. Вимірювання здійснювали на приладі ТР-5006 ГОСТ 23677-79 за шкалою Н за допомогою кульки Ø 3.175 з навантаженням 588.4 Н за стандартною методикою $[6,18]$.

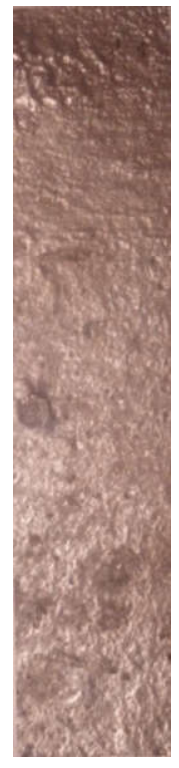

1

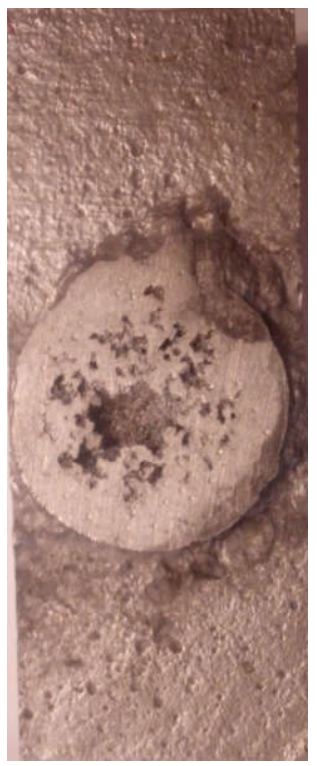

2

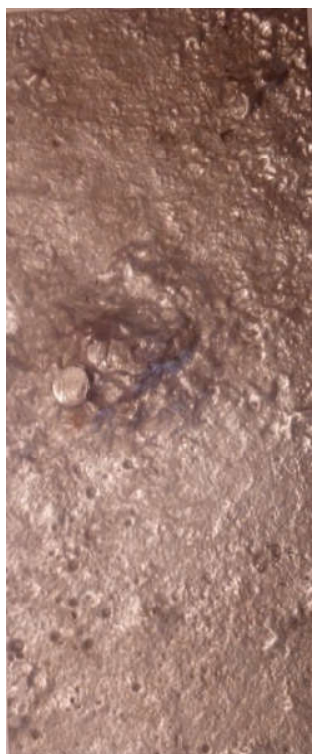

3

Рисунок 2 - Зразки для експериментальних досліджень:

№ 1- 3 малим випором; № 2- з ливником; № 3- 3 великим випором 


\section{Статистичне опрацювання та обговорення результатів досліджень}

На підставі експериментальних досліджень у середовищі Mathcad 15 обчислили коефіцієнти гомогенності Вейбулла $(m)$ за формулами (2-4) i технологічну пошкоджуваність матеріалу виливка $D$ за формулою (8). Зміна коефіцієнта гомогенності $(m)$ і технологічної пошкоджуваності $D$ по товщині (глибині) виливка приведена на рис. 3.

Результати експериментальних досліджень структури та пошкоджуваності литої заготовки свідчать про наступне.

1. Найбільша кількість технологічних дефектів характеризує структурні зони матеріалу виливка на глибині до 2 мм від поверхні для зразка із ливником порівняно із зразком з малим випором. Зі сторони малого випора цей вплив інтенсивніший, зі сторони великого випора - слабший (рис. 3). Це визначається особливостями кристалізації матеріалу, наявністю домішок і неоднорідностей у поверхневому шарі та усадкової раковини, зміщеної від вісі симетрії та зорієнтованої у напрямку до малого випора, та підтверджується мінімальними значеннями коефіцієнта гомогенності Вейбулла $(m)$, а також максимальними значеннями технологічної пошкоджуваності $D$. У зв'язку з цим шар металу на глибині 2 мм від поверхні підлягає механічному обробленню для всіх видів заготовок.
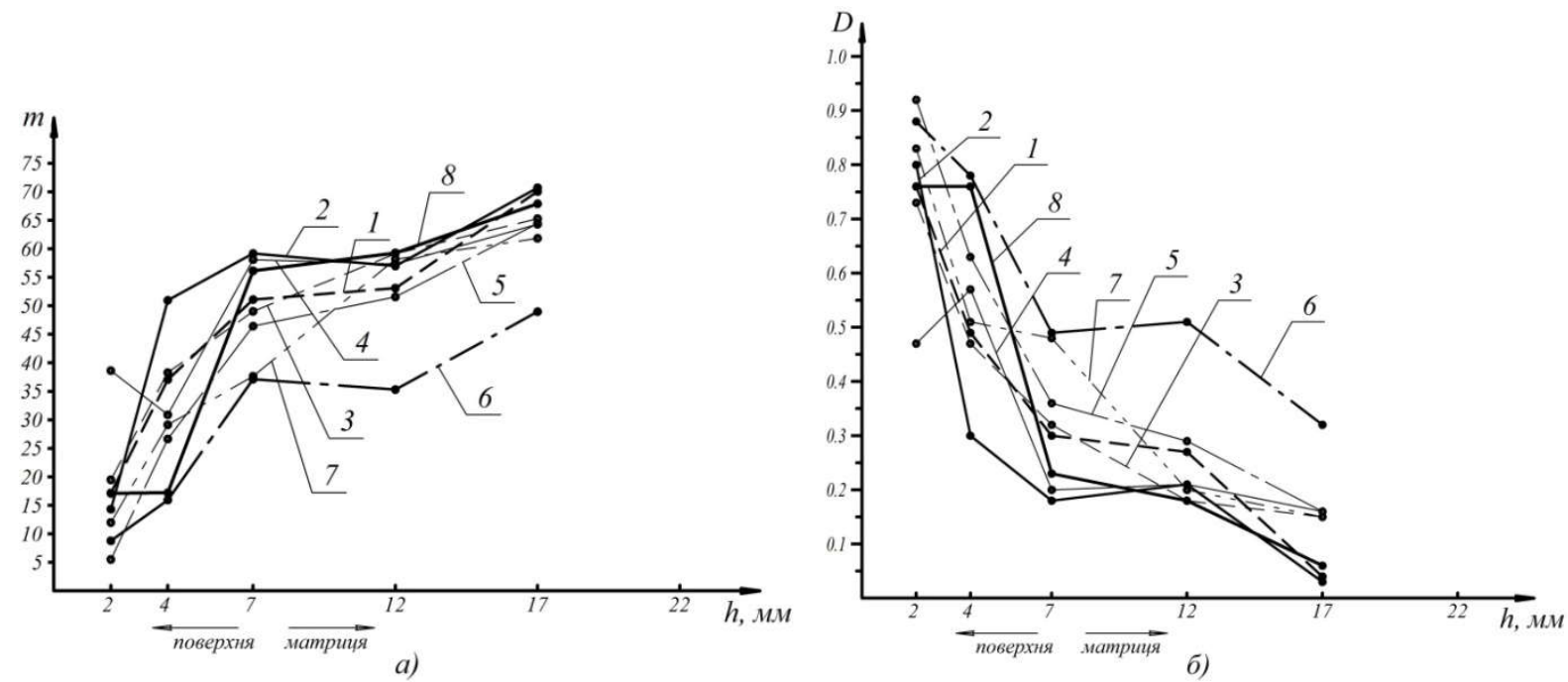

Рисунок 3 - Графіки залежностей коефіцієнта гомогенності m (a) і пошкоджуваності матеріалу D (б) по висоті для зразків № 1 і № 2: 1, 2 - від випора малого для першої та другої серії дослідів відповідно; 3, 4 - 3 протилежного торця від випора малого для першої та другої серії дослідів відповідно; 5, 6 - для ливника зі сторони випора малого для першої та другої серії дослідів відповідно; 7, 8 - для ливника зі сторони випора великого для першої та другої серії дослідів

2. При переміщенні від поверхні до основного матеріалу у перерізах від 2 до 4 мм спостерігається тенденція до зменшення технологічної 
пошкоджуваності для зразка з малим випором при переході від першої до другої фрезерної обробок (рис. 3). Поряд з тим в розглядуваних перерізах зі сторони від ливника пошкоджуваність $є$ вищою, що свідчить про вплив елементів конструкції форми на розподіл домішок i неоднорідностей у структурних зонах виливка. Для зразка із ливником технологічна пошкоджуваність зростає при переміщенні до усадкової раковини для другої серії дослідів.

3. Подальше переміщення від поверхні заготовок до основного матеріалу у перерізах від 4 до 17 мм супроводжується зменшення технологічної пошкоджуваності матеріалу $D$. Стабілізація процесу (зменшення динаміки зміни величини $D$ ) починається із глибини 7 мм, що підтверджується зростанням значень коефіцієнта гомогенності Вейбулла $(m)$ i їх наближенням до раціональних значень (рис. 3). Однак для перерізу ливника (зі сторони малого випора) переміщення до його центру супроводжується зменшенням значень коефіцієнта гомогенності Вейбулла $(m)$ при переході від першої до другої серії. Такі результати пояснюються впливом наявної усадкової раковини на еволюцію домішок та фізико-хімічних дефектів структури.

4. На підставі аналізу результатів експериментальних досліджень (рис. 3) встановлено, що для зразка із випором мінімальна глибина дефектного шару із максимальною кількістю технологічних пошкоджень рівна 4 мм зі сторони власне випора і 7 мм з протилежного від малого випора торця. Для заготовки із ливником мінімальне значення припуску зі сторони великого випора складає 7 мм. Переріз ливника зі сторони малого випора характеризується значною схильністю до технологічної пошкоджуваності при менших порівняно 3 іншими перерізами значеннями коефіцієнта гомогенності Вейбулла $(m)$ за навіть на глибині до 17 мм, що пояснюється близькістю усадкової раковини 3 огляду на це раціональним варіантом буде утилізація зразка із ливником.

\section{Висновки}

Розроблено методику оцінювання впливу елементів конструкції виливка на прогнозування розвитку структурних дефектів і неоднорідностей у його матеріалі. Запропоновано критерій технологічної пошкоджуваності при застосуванні методу LM-твердості для аналізу структурних змін при виготовленні литих заготовок за ступенем розсіювання характеристик твердості матеріалу. На підставі результатів експериментальних досліджень встановлено мінімальні значення припусків на оброблення литих заготовок із концентраторами напружень із алюмінієвого сплаву. 


\section{ЛIТЕРАТУРА}

1. Проников А.С. Надежность машин / А.С. Проников. - М.: Машиностроение, 1978. - 592 с.

2. Проников А.С. Параметрическая надежность машин / А.С. Проников. - М. : Изд.-во МГТУ им. Н.Э. Баумана, 2002. - 560 с.

3. Божидарнік В.В., Григор'єва Н.С., Шабайкович В.А. Технологія виготовлення деталей виробів: навч. посібник / В.В. Божидарнік, Н.С. Григор'єва, В.А. Шабайкович. - Луцьк: Надстир'я, 2006, 612 с.

4. Strelnikov V. The Status and Prospects of Reliability Technology - Part 1 / V. Strelnikov // RAC Jornal. - 2001. - № 1. - P. 1-4.

5. Strelnikov V. The Status and Prospects of Reliability Technology - Part 2 / V. Strelnikov // RAC Jornal. - 2001. - № 2. - P. 8-10.

6. Kusyi Ya.M. Investigation of the technological damageability of castings at the stage of design and technological preparation of the machine Life Cycle / Ya.M. Kusyi, , A.M. Kuk // Journal of Physics: Conference Series. - 2020. - Volume 1426. https://iopscience.iop.org/article/10.1088/17426596/1426/1/012034/pdf. doi:10.1088/1742-6596/1426/1/012034.

7. Болотин В.В. Прогнозирование ресурса машин и конструкций / В.В. Болотин. - М.: Машиностроение, 1984. - 312 с.

8. Болотин В.В. Ресурс машин и конструкций / В.В. Болотин. - М.: Машиностроение, 1990. - 448 c.

9. Кузін О.А., Кузін М.О. Структура і міжзеренна пошкоджуваність сталей / О.А. Кузін, М., О. Кузін // Українська академія друкарства, наукові записки. - 2013. - № 4 (45). - С. 99-115.

10.Закалов О.В., Закалов І.О. Основи тертя і зношування в машинах: навчальний посібник / О.В. Закалов, І.О. Закалов. - Тернопіль: Видавництво ТНТУ ім. І.Пулюя, 2011. - 322 с.

11.Кусий Я.М. Оптимізація маршруту оброблення поверхонь заготовки за критерієм однорідності структури матеріалу /Я.М. Кусий // Системні технології. 2021. № 1(132). С. 76-91.

12.Murakami S. Continuum Damage Mechanics - A Continuum Mechanics Approach to the Analysis of Damage and Fracture. / S. Murakami - Springer, Dordrecht, Heidelberg, London, New York, 2012. - $402 \mathrm{p}$

13.Кусий Я.М., Кузін О.А., Кузін М.О. Вплив технологічного маршруту оброблення на формування міжзеренної пошкоджуваності виливків / Я.М. Кусий, О.А. Кузін, М.О. Кузін // Східно-європейський журнал передових технологій. - 2016. - № 1/5 (79). - С. 39-47.

14.Lebedev A.A., Muzyka N.R., Volchek N.L. A new method of assesment of material degradation during its operating time / A.A. Lebedev, N.R. Muzyka, N.L. Volchek // Zaliznychnyi Transport Ukrainy. - Vol. 5. - 2003. - P. 30-33.

15.Швець В.П., Музика М.Р., Маковецький І.В. [i ін.] Контроль поточного стану металу стрілкового переводу в процесі напрацювання. Проблемы прочности. 2011. № 1. С. 104-108.

16.Лебедев А.А., Ламашевский В.П., Музыка Н.Р. [и др.] Кинетика накопления рассеянных повреждений в поликристаллических материалах с разным размером зерна при малых деформаціях. Проблемы прочности. 2011. № 5. С. 32-44.

17. Muzyka N.R., Shvets V.P. Effect of a Loading Mode on Damage Accumulation in the Material. Strength of Materials. 2014. № 46(1). P. 105-109.

18. Kusyi Ya., Stupnytskyy V. Optimization of the Technological Process Based on Analysis of Technological Damageability of Casting / Ya. Kusyi, V. Stupnytskyy // Advances in Design, Simulation and Manufacturing III. Proceedings of the 3rd International Conference on Design, Simulation, Manufacturing: The Innovation Exchange, DSMIE-2020, June 9-12, 2020, Kharkiv, Ukraine. - 2020. - Volume 1: Manufacturing and Materials Engineering. - P. 276-284. 


\section{REFERENCES}

1. Pronikov A.S. Machines reliability / A.S. Pronikov. - Moscow: Mechanical engineering, 1978. - 592 p. (in Russian)

2. Pronikov A.S. Parametric reliability of machines / A.S. Pronikov. - Moscow: Bauman Moscow State Technical University Publishing House, 2002. - 560 p. (in Russian)

3. Bozydarnik V.V, Grygorjeva N.S., Shabajkovych V.A. Technology of manufacturing parts of products: a textbook / V.V. Bozydarnik, N.S. Grygorjeva, V.A. Shabajkovych. - Lutsk: Nadstyrja, 2006, 612 p. (in Ukrainian)

4. Strelnikov V. The Status and Prospects of Reliability Technology - Part 1/ V. Strelnikov // RAC Jornal. - 2001. - № 1. - P. 1-4.

5. Strelnikov V. The Status and Prospects of Reliability Technology - Part 2 / V. Strelnikov // RAC Jornal. - 2001. - № 2. - P. 8-10.

6. Kusyi Ya.M. Investigation of the technological damageability of castings at the stage of design and technological preparation of the machine Life Cycle / Ya.M. Kusyi, , A.M. Kuk // Journal of Physics: Conference Series. - 2020. - Volume 1426. https://iopscience.iop.org/article/10.1088/17426596/1426/1/012034/pdf. doi:10.1088/1742-6596/1426/1/012034.

7. Bolotin V.V. Prediction of machines and structures resourse / V.V. Bolotin. - Moscow: Mechanical engineering, 1984. - 312 p. (in Russian)

8. Bolotin V.V. Resource of machines and structures / V.V. Bolotin. - Moscow: Mechanical engineering, 1990. - 448 p. (in Russian)

9. Kuzin O.A., Kuzin N.O. Structure and intergrain damageability of steels / O.A. Kuzin, N.O. Kuzin // Ukrainian Academy of Book Printing, scientific notes. - 2013. - № 4 (45). - P. 99-115. (in Ukrainian)

10.Zakalov O.V., Zakalov I.O. Fundamentals of friction and wear in machines: a textbook / O.V. Zakalov, I.O. Zakalov. - Ternopil: Publisning of TNTU named I.Puluj, 2011. - 322 p. (in Ukrainian)

11.Kusyi Yа.М.Оптимізація маршруту оброблення поверхонь заготовки за критерієм однорідності структури матеріалу / Үa.M. Kusyi // System Technologies. 2021. № 1(132). P. $76-$ 91. (in Ukrainian)

12.Murakami S. Continuum Damage Mechanics - A Continuum Mechanics Approach to the Analysis of Damage and Fracture. / S. Murakami - Springer, Dordrecht, Heidelberg, London, New York, 2012. - $402 \mathrm{p}$.

13. Kusyi Ya.M., Kuzin O.A., Kuzin N.O. Influence of treatment technological route on castings grain damaged forming / Ya.M. Kusyi, O.A. Kuzin, N.O. Kuzin // Eastern-European Journal of Enterprise Technologies. - 2016. - № 1/5 (79). - P. 39-47. (in Ukrainian)

14.Lebedev A.A., Muzyka N.R., Volchek N.L. A new method of assesment of material degradation during its operating time / A.A. Lebedev, N.R. Muzyka, N.L. Volchek // Zaliznychnyi Transport Ukrainy. - Vol. 5. - 2003. - P. 30-33.

15. Shvets V.P., Muzyka N.R., Makovetskii I.V. [at all] Control of the current state of the turnout metal in the operational process. Strength of Materials. 2011. № 1. P. 104-108. (in Ukrainian)

16.Lebedev A.A., Lamashevskii V.P., Muzyka N.R. [at all] Kinetics of scattered damages accumulation in polycrystalline materials with different grain sizes at small deformations. Strength of Materials. 2011. № 5. P. 32-44. (in Russian)

17.Muzyka N.R., Shvets V.P. Effect of a Loading Mode on Damage Accumulation in the Material. Strength of Materials. 2014. № 46(1). P. 105-109.

18. Kusyi Ya., Stupnytskyy V. Optimization of the Technological Process Based on Analysis of Technological Damageability of Casting / Ya. Kusyi, V. Stupnytskyy // Advances in Design, Simulation and Manufacturing III. Proceedings of the 3rd International Conference on Design, Simulation, Manufacturing: The Innovation Exchange, DSMIE-2020, June 9-12, 2020, Kharkiv, Ukraine. - 2020. - Volume 1: Manufacturing and Materials Engineering. - P. 276-284.

Received 01.02.2021.

Accepted 11.02.2021. 
UDK 621.9.015:621.9.019

\section{INFLUENCE OF DESIGN ELEMENTS OF THE CASTING ON THE EVOLUTION OF TECHNOLOGICAL DEFECTS}

The formation of product quality parameters, their performance characteristics and reliability indicators are closely related with the important substages and stages of the Products Life Cycles. The differences between the predicted and real values of the functional parameters of products during their Life Cycles indicate the disadvantages in the solving of the tasks using only the theoretical methods. The initial structure and initial properties of the blanks should be considered in close relations with the heredity of the material, starting from the melt smelting. About $25 \%$ of the quality parameters of the original material are transferred from the blank, and about $75 \%$ are formed during casting and crystallization of the liquid melt during cooling. The local nature of fracture during cutting determines to needs to analyze the process of accumulation of technological defects in materials (alloys) and predict their degeneration into the technological damages under adverse operating conditions of products. The method of LM-hardness, developed under the guidance of Academician A.O Lebedev, are used effectively to solve applied engineering problems. A characteristic feature of the LM - hardness method is to use of the degree of scattering of the characteristics of the mechanical properties of the material samples after operation at different stress levels, such as hardness, for the analysis of material damages degree. The actual damages degree of the product material and the intensity of its increasing are used to analyze the processes of material degradation during the operation stage of the machine parts. In this paper a criterion of technological damageability of the product material for the analysis of structural changes during castings manufacturing is proposed. Experimental researches for casting in sand molds from aluminum alloy AK21M2.5H2.5 GOST 1853-93 are realized. Based on the results of experimental studies, the distribution of technological defects in the material is determined and the minimum values of allowances for processing of aluminum alloy castings with stress concentrators are established.

Keywords: blank, casting, Product Life Cycle, technological process, technological inheritability, homogeneity, technological damageability.

Кусий Ярослав Маркіянович - к.т.н., доцент, докторант кафедри робототехніки та інтегрованих технологій машинобудування Національного університету «Львівська політехніка».

Личак Олег Васильович - к.т.н., с.н.с. відділу № 9 методів та засобів відбору й обробки діагностичних сигналів ФМІ ім. Г.В. Карпенка НАН України.

Кусый Ярослав Маркиянович - к.т.н., доцент, докторант кафедры робототехники и интегрированных технологий машиностроения Национального университета «Львовская политехника».

Лычак Олег Васильевич - к.т.н., с.н.с. отдела № 9 методов и средств отбора и обработки диагностических сигналов ФМИ им. Г.В. Карпенка НАН Украины.

Kusyi Yaroslav - PhD, associate professor, Doctoral Candidate of the Department of Robotics and Integrated Mechanical Engineering Technologies of Lviv Polytechnic National University (Ukraine).

Lychak Oleh - PhD, senior researcher at Karpenko Institute for Physics and Mechanics National Academy of Sciences of Ukraine. 